\title{
14 Disrupting the second oldest profession
}

\section{The impact of cyber on intelligence}

\author{
Danny Steed
}

The practice of intelligence has undergone numerous challenges throughout its history, particularly since the 12 th century when permanently standing, professionalized intelligence services were established. The challenge posed by the rise of cyberspace has, however, arguably proved one of the most severe against which intelligence would have to adapt. The end of the Cold War served to present intelligence with a dual challenge. First, the end of the Cold War also ended the known international order, removing the primary raison d'être for the intelligence services itself. This raised the legitimate, but of course ultimately incorrect, concern that intelligence itself "is a dying business" (Adams 1994: 316).

Second, and most important to this chapter, was the maturation of three key technologies - the personal computer (PC), email, and the World Wide Web - that served to, if not invent, then certainly to catalyze the information revolution exponentially. By coinciding with the end of the Cold War, the maturation of these technologies laid the foundations for cyberspace as we now know it, thereby presenting a new challenge for intelligence communities to consider: How to maintain their craft during the change from the analog world in which they had become so proficient, to the vastly more open, connected, and intrusive digital one.

This is the motivating concern behind this chapter, how the intelligence world adapted to the challenges presented by the digital age. In doing so, it will be revealed how the actions taken by those very actors in order to retain their relevance to the pursuit of security not only pioneered (Buchanan 2020: 329) the methods for intelligence in the digital age but have disproportionately disrupted cyber in turn. This disruption from intelligence is playing a leading role in the transformation of cyber security politics, driving socio-technological uncertainties through their practices, perhaps so far as to exacerbate the fragmentation of geopolitical interests themselves, as this author will argue.

The chapter will proceed first by detailing the nature of the digital challenge that was presented to the intelligence world at the end of the Cold War, before detailing the specific actions of American and British intelligence agencies to "master the internet". The main focus of the chapter will then move on to the consequences of intelligence actions on the politics of cyber security itself. By examining three core areas of socio-technological uncertainty that are impacted the evolution of secrecy, intelligence as agents of proliferation, and intelligence as 
shapers of norms - it will be demonstrated that the second oldest profession has in fact disrupted and fragmented cyber security politics far more than the arrival of cyber did the intelligence profession.

The intelligence world, who were once the invisible actors constituting the "missing dimension" (Andrew and Dilkes 1985) in the international system, through their exploitation of disruptive cyber tools and adapting to the sociotechnological transformation of the digital age, have very much become central, perhaps even dominant, actors in the international system driving the fragmentation of cyber security politics. For better or for worse, the spies have migrated from the shadows into the very code and fiber that everyone worldwide uses.

\section{The transformation: Challenge, fear, and opportunity}

Whyte and Mazanec are right to declare that there has been an "unbreakable marriage between computers and espionage" (Whyte and Mazanec 2019: 61), so closely aligned has been the development of the technology with the practice of spying. The origins of the computer itself lie at the heart of the Allied successes in breaching Nazi codes during the Second World War, Enigma the most famous among them (Whyte and Mazanec 2019; Andrew 2018). The sternest challenge to be posed by the technologies that espionage has been "intimately connected" (Lowenthal 2018: 34) with would only truly emerge in the post-Cold War years, when those very technologies challenged the entire infrastructure on which intelligence had been built for decades, the shift from the analog to the digital world.

The challenge became one of migrating intelligence skillsets from the analogue expertise centered on cryptography for decades, to one that could penetrate digital codes and infrastructures. That shift was to take the intelligence world away from an infrastructure it had come to know well, that of listening outposts, telegraph stations, and transmitters that enabled passive gathering. During this time in the early 1990s, the American National Security Agency (NSA) - then led by Rear Admiral William Studeman - had commissioned an internal "Global Access Study" (Kaplan 2017: 41-44), aimed at projecting long-term access to the information the NSA required to fulfil its functions. It offered a vision of a world migrating to the digital age, where the intelligence gathering infrastructure, which had been established over many decades, would gradually decrease in relevance

as the world's information flows left the electromagnetic spectrum and migrated into fiber optics as ones and zeros instead.

The motivating fear behind intelligence community evolution was clear, to avoid the situation of "going dark" and being cut off from essential sources of necessary information. Where global information and communications flow migrate, so too must the eyes of the intelligence community. As the 1990s progressed, the NSA study was being proven correct; a clear shift in reality was observed across the world where traditional radio receivers and antennas were no longer picking up signals, or certainly they were picking up far reduced traffic (Kaplan 2017: 35). The actions taken to change with the evolving world presented a potentially golden opportunity to the intelligence community, summed up best by the 
inventor of the World Wide Web himself, Tim Berners Lee: "to allow links to be made to any information anywhere" (Berners-Lee 1991).

Numerous practical challenges needed to be navigated, that included a closer alignment with the private sector, as the private sector owned much of the infrastructure that needed accessing (Clemente, in Goodman and Hillebrand 2014: 259). Speed was also a key factor; Degaut illustrates this well in stating that the information revolution changed the dynamic where policymakers were once almost entirely reliant on the intelligence community for insights. Intelligence "now has to compete for policymakers attention" (Degaut 2016: 510) with the multitudes of sources, both traditional and new, who have also been enabled by the vast data flows on offer. A mission statement from former NSA Director Keith Alexander to solve this is very illustrative:

Let's collect the whole haystack ... Collect it all, tag it, store it ... And whatever it is you want you go searching for it.

(Alexander in Nakashima and Warrick 2013)

The old intelligence adage - to find the needle in the haystack - very simply cannot take place without access to the haystack in the first place (Kaplan 2017: 262). The intelligence solution to this problem relied on exploiting, above all, sovereign geographic access to the submarine cables on which the bulk of the internet traffic traverses. Specifically, the cables that land from the American east coast - Apollo North, TAT-8, TAT-14, and AC-2 (Harding 2014: 214) - to the British South West Coast. In combination with Britain's key geographic position, these landing points become a unique communications hub due to the sheer percentage of global traffic pushed between these two points. Estimates can vary, but perhaps up to $25 \%$ of global internet traffic traversed the cabling infrastructure that lands in Cornwall (Harding 2014: 215) by the start of the 2010s.

What matters here is less an exhaustive counting of where traffic is intercepted, but rather in how the data is processed. For what is essentially the world's largest ever phone tap, the British Government Communications Headquarters (GCHQ) and the NSA had indeed "mastered the internet" (MacAskill, Borger, Hopkins, Davies and Ball 2013) through their TEMPORA and PRISM programs. Regarding TEMPORA, GCHQ's key breakthrough lay less in tapping the cables themselves than in innovating a buffer system, whereby internet information could be cached for automated analysis for up to three days, with broader metadata held for up to 30 days (Gill and Phythian 2018: 150). "Analysts and data miners would then retroactively be able to sort through this vast pool of digital material" (Harding 2014: 220). The operation, known under the code name Tempora, would intercept "all forms of online activity" (Greenwald 2014: 116) for this method of retrospective analysis.

PRISM, meanwhile, operated in partnership with numerous big technology corporations to facilitate access and sharing. In his leaks, Snowden specifically named Microsoft, Yahoo!, Google, Facebook, Paltalk, YouTube, Skype, and 
Apple as willing participants to enable the NSA to gather browsing data as an "upstream collection" strategy (Snowden 2019: 347). Snowden then details two further tactical tools, TURMOIL and TURBINE. TURMOIL was a passive tool to filter all traffic. "Seeing your request, it checks its metadata for selectors ... that mark it as deserving for more scrutiny" (Snowden 2019: 347). If flagged, that data is referred to TURBINE, designed to actively engage the user by determining which software exploits to send to the user and deploy them with the objective of surveiling that user (Snowden 2019: 348).

In tandem, the NSA and GCHQ had provided the prerequisite for competing in the digital age, to have the information to begin with. Mastering the internet required, first and foremost, collecting the entire haystack. Or, as another now well-known phrase describes the dynamic: "Getting information from the internet is like taking a drink from a fire hydrant". ${ }^{1}$ American and British intelligence had solved how to fully absorb that information, subject it to automated analytics, and prioritize the findings for further action.

\section{The consequences of intelligence actions on cyber security politics}

While the intelligence community may have mastered the internet and developed strategies to remain effective, their actions bring with them wider consequences that must be considered. There are three consequences of socio-technological uncertainty causing political fragmentation that intelligence community actions highlight which are worthy of consideration here: Secrecy, proliferation, and norms.

First is secrecy, or rather the evolving meaning of secrecy. Secrecy, as Tucker argues well, enjoys a strange relationship in liberal nations, he notes that in early modern Europe "before the rise of liberalism, secrecy was synonymous with advantage and greater power" (Tucker 2014: 31). Liberalism, however, reversed the dynamic fundamentally in favor of the individual, developing a presumption against secrecy in politics, favoring privacy for the people instead. "Government became public, open; the people gained a right to privacy" (Tucker 2014: 35). This reversal was, of course, imperfect, carrying with it an inherent tension between the needs of the state to ensure security, versus the need to intrude upon the liberties enjoyed by the people. Privacy versus liberty is thus eternally in tension with regard to the work of intelligence agencies; it is a dynamic that is forever susceptible to the uncertainties brought by new innovations and technologies, and one that is always liable to fragmentation and rebalancing.

Until recent decades, intelligence agencies in the Western nations have mostly operated by avoiding this tension as far as possible through a series of means intended to conceal their operations. In the UK, this included not basing the intelligence agencies on any statutory footing at all until the 1980s and, even when they were codified in law, those laws afford significant protections and exemptions from other laws. For example, the UK Intelligence Community is afforded blanket exemption from the Freedom of Information Act (2000) and Public Records Act 
(1958). Lustgarten's conclusion still remains very much valid in explaining the meaning of such approaches, that the "brevity of British statute reflects the fact that it is largely a cloak draped over an unchanged figure, not intended to disturb existing working relationships" (Lustgarten and Leigh 1994: 424).

The Information Revolution has, however, disturbed and fragmented those relationships, by forcing intelligence agencies to operate in the same environment as everyone else. The arrival of disruptive cyber tools increased the scope of uncertainty faced by intelligence actors. In this regard Peter Swire's assessment is most apt in arguing that there is now a "declining half-life" (Swire 2015) to secrets in intelligence. Swire argues convincingly that intelligence can no longer enjoy the "Cold War luxury" of operating in geographically distinct infrastructures, because civilian and intelligence targets alike "use the same operating systems, encryption protocols, apps, and other software" (Swire 2015: 4).

In a congested and constantly contested environment, spies carry increased risk that reduces their ability to keep secrets in two ways, intrusion detection and the leaking of methods. First, intelligence is rarely a purely passive activity, active intrusive methods are also needed. Indeed, as Whyte and Mazanec rightly point out, there is little technical difference between access and exploitation, the difference lying in "the intentions of those who hack for intrusive or disruptive purposes and the kinds of effects they are able to cause" (Whyte and Mazanec 2019: 76). Fundamentally the risk is as Swire states, that "intrusion carries with it the risk of intrusion detection" (Swire 2015: 5) and nowhere more so than online where monitoring occurs constantly and by automation; intelligence intrusions can simply be exposed far faster than before, bringing with it unwelcome levels of transparency. Access can also be lost with incredible speed, as Michael Hayden states, months spent gaining privileged access "can be lost with a casual upgrade of the targeted system" (Hayden 2016: 210). Such decreased windows of opportunity only incentivize intrusive measures, to use exploits before they expire, which of course increases the risk of regular operational compromise.

Not only are intelligence activities at greater risk of frequent detection, their sources and methods are now harder to keep secret, which is the second area of reduced capability. Leaks are of course the primary vehicle of exposing intelligence methods, as seen through leaks perpetrated by WikiLeaks, Chelsea Manning, and Edward Snowden throughout the 2010s. Snowden, in particular, has brought to the fore methods that may have remained unearthed for many years otherwise, raising questions about the legitimacy of intelligence actions and responsible behavior. Yet intelligence methods are also exposed via the nature of cyber tools themselves, specifically their code. Unlike traditional weaponry, code is not destroyed after use and can be forensically analyzed, reverse-engineered, or simply copied and deployed by other actors.

This leaking of methods is closely linked to the second consequence of sociotechnological uncertainty, which is that intelligence agencies have become a source of proliferation in cyberspace. Exposure of intelligence methods educates other users how to act in the same vein, but for entirely different purposes. This is because, revisiting Swire's note, when everybody uses the same platforms, 
protocols, operating systems, and applications, methods are immediately transferable. The proliferation of intelligence tools (regardless of the means by which they were acquired) arms, for lack of a better phrase, other actors throughout cyberspace, and can only be approached as a significant consequence of sociotechnological uncertainty that contributes to greater political fragmentation in this space.

This is because while there are always concerns regarding the legitimacy of intelligence actions, certainly in the liberal nations great efforts are expended to ensure levels of transparency on their work. For those who are the beneficiaries of intelligence tools and methods proliferation, there can be no such assurance of responsible or legitimate use in the eyes of the law, as well as an almost zero possibility of ensuring oversight. After all, how can legitimate authorities ensure transparency over a multitude of enabled actors outside the security space who have been armed anonymously? The more who become armed and enabled in this fashion, arguably only adds to an increased environment of cyber insecurity, thereby serving to further fragment cyber security politics.

Before offering a tangible example of this proliferation, however, it is necessary to briefly address the debate as code classifying as a cyber "weapon" or not. Analogizing code to weapons proves useful particularly in an illustrative function relating to proliferation, but it is wise to note the resistance to such classification by Thomas Rid. Rid bases his position on the view that computer code does not carry the same coercive power (the power to kill), that weaponry as traditionally viewed does, and risks being no more than a category error (Rid and McBurney 2012). The lack of proof in coercive abilities is a view shared and developed by Valeriano, Jensen, and Maness, who remain unconvinced by the empirical scorecard of cyber operations to achieve more than limited political objectives (Valeriano et al. 2018). Lucas Kello, by contrast, finds the "absence of death and the intangibility of most direct effects are not convincing grounds" and offers the term "virtual weapon" centrally in his argument (Kello 2017: 61).

Ground between these two positions is being established, however. Lin and Zegart offer a series of unique characteristics in order to think in a strategic context, specifically: Tools to gain intelligence versus those inflicting damage are difficult to distinguish; offensive cyber operations act on intangible targets; the target's characteristics themselves greatly impact the effectiveness of the attack; prior interaction with a target is often a prerequisite ahead of an actual cyberattack; and that cyberspace targets are often fleeting, liable to disappear in ways unlike physical targets (Lin and Zegart 2018: 607). Van Puyvelde and Brantly, meanwhile, are wise to have adopted a compromise position between the above camps, carrying the general classification of cyber "capabilities", noting that as capabilities expand and develop, so too will the debate itself (Van Puyvelde and Brantly 2019: 74).

Proliferation of this type is exactly what happened in 2017 when the hacker group "Shadow Brokers" compromised an NSA staging server, taking possession of a large cache of tools reportedly developed by the NSA's secretive Tailored Access Operations unit (Herrington, in Andrew et al. 2020: 578-579). Among 
these tools was an exploit named "EternalBlue", which worked against a vulnerability in all Windows systems prior to Windows 8, specifically the Server Message Block (SMB) function that could enable remote code execution (Greenberg 2019: 301-302). Following a wider release of the exploit by the Shadow Brokers, it was appropriated and deployed in two global ransomware attacks, WannaCry and NotPetya in 2017. In the UK, the WannaCry attack became notable for its impact on the National Health Service - arguably the attack's most famous victim - paralyzing $35 \%$ of all hospital trusts in the UK ( 80 out of 236) among many hundreds of other health organizations (NAO 2018: 11). NotPetya meanwhile, became the first cyberattack to cost more than US $\$ 10$ billion in losses worldwide, costing global corporations Maersk and FedEx at least US\$300 million each (Greenberg 2019: chapter 27).

The global ransomware attacks of 2017, armed at their core with exploits developed by the NSA, must be regarded as a seminal example of intelligence agencies becoming inadvertent proliferators in cyberspace. As Greenberg states, instead of any hypothetical fear of inspiring non state or hostile state actors to behave in certain ways and develop their own tools, “America's hacking arsenal had fallen, suddenly and directly, into enemy hands" (Greenberg 2019: 290). Sanger is in agreement in arguing that some levels of secrecy are no longer required among nation-states because "after Snowden and the Shadow Brokers, there is not much mystery left” (Sanger 2018: 566). By occupying the same infrastructure on cyberspace as other users, intelligence agencies are also vulnerable to thefts and data breaches, carrying consequences that WannaCry and NotPetya proved are not hypothetical in their ability to cause harm, and perhaps lending greater credence to Kello's position that code is increasingly a weapon.

The third and final consequence of socio-technological uncertainty is that intelligence agencies have become, as Georgiva argues, unexpected norm-setters (Georgiva 2020). Noting the previously established history of intelligence agencies enjoying significant statutory protections domestically, Georgiva establishes well that this ambiguity also extends into international law, with precious little consensus on whether it is legal or illegal (Georgiva 2020: 42). This is also reflected in the Tallinn Manual, stating that "International law does not directly address peacetime espionage as such" (Schmitt 2017: 25). This is a legal ambiguity that is increasingly becoming a concern because "many of the exposed cyber operations set alarming precedents" (Broeders et al. 2019: 2) that are more and more difficult to ignore.

This legal ambiguity, combined with the reality that in the information age those whose craft is information itself should be primary actors, contributes to a security dynamic. This dynamic is that intelligence holds a legitimate purpose as security actors in the pursuit of their objectives. At the same time, however, the digital "unpeace" (Kello 2017: 249) is exacerbated by their actions and behaviors, setting normative precedents that encourage - and through inadvertent proliferation, both educate and arm - multitudes of other actors, whether state or non-state in their various guises. Making a judgment on whether such normative setting behavior is correct or in need of redress is beyond the scope of this chapter's 


\section{Danny Steed}

focus. Suffice to say however one must question Georgiva's call that intelligence behaviors be incorporated into the calculus of norm-building agendas, whether at the UN or otherwise (Georgiva 2020: 48).

The history of intelligence practice to date has largely been one of crafting deliberate ambiguity in as many arenas as possible - domestic and international law being the most tangible - to enable the spies to operate. Generally, the logic has rested on the Cold War era reasoning, which hopes involuntary intrusion into the sovereign affairs of actors serves to provide sufficient enough transparency among other actors and avoid escalations. In this vein, intelligence is to be seen as a form of steam valve to help depressurize the international order from movements toward large-scale confrontation and war. It is a view that, so far, can be argued as having been effective enough following the Total Wars period. Altering the state of deliberate ambiguity that intelligence has enjoyed so far may address some aspects of cyber security, but it is also highly likely to carry unforeseeable consequences that extend far beyond the affairs of cyberspace into other arenas of geopolitics. Intelligence actions in the digital age certainly contribute to increased insecurity in cyberspace, but their overall mission is likely to still yield a net positive impact on depressurizing global security tensions.

\section{Cyber disrupting intelligence, or intelligence disrupting cyber?}

What is clear from this exploration and the argument by Georgiva that intelligence agencies are not only shaping, but driving normative behavior in cyberspace, is that the disruption that intelligence is having on cyberspace is arguably larger and more politically significant than those that cyberspace wrought on the practice of intelligence itself. Policymakers and lawmakers face acute difficulties in navigating the challenges posed by this reality; the Snowden revelations have served to arm actors such as China, and even American allies, with the charge of hypocrisy at Western nations who preach a "rules-based order". Similarly, American complaints at Intellectual Property theft online can easily be met with reminders that espionage is not expressly prohibited in international law. As Dunn Cavelty rightly points out, when intelligence agencies are expected to operate "unfettered and without restraint" internationally, they present themselves as the biggest issue (Dunn Cavelty 2018a: 118).

In an international system where security is a legitimate pursuit, a cyberspace where "everyone favors insecurity" becomes in fact desirable (Schneier 2018: 83). This creates a problem in the pursuit of security, as established by Dunn Cavelty that "the security of cyberspace and security by (or through) cyberspace are often diametrically opposed" (Dunn Cavelty 2018b: 27). In this case, the pursuit of security through the exploitation of cyberspace as a means to an end significantly impacts the security of cyberspace itself. The fear ultimately becomes that while some actors become skilled at the pursuits of security through cyberspace for their own objectives, in doing so they continue to make that very cyberspace ever more the "wild, wild West" that President Obama described it as in 2015 (Obama 2015). 
With these points in mind, a fruitful avenue for scholarship to consider is to revisit a seminal Cold War concept in international relations theory, the security dilemma. Here, the traditional concept established by Robert Jervis is considered, that one state's actions to increase its security inherently decreases that of the others (Jervis 2007). Much of Jervis' conceptual framework applies well to considerations of cyber security, especially the difficulty in determining defensive tools and behaviors from offensive ones, and the relative cost and balance between the offence and defense in its centrality to decision-making (Jervis 2007: 145-146). Yet although these are eminently valid considerations for scholars to use, it is instead the environmental, structural element of Jervis' thesis that matters most to this argument.

Specifically, it is the consideration that the dilemma results primarily not from the actions of actors, but instead from the structure of the international system itself (Griffiths et al. 2002: 295), which locks and incentivizes securityseeking behavior from the outset. Brantly has previously established the place of the security dilemma within cyber security politics, highlighting how the characteristics of cyberspace lends itself as being a place of anarchy and order at the same time. "There are rules defined by code and architecture, and at the same time the current of information and ideas has historically been considered a realm free of governance" (Brantly 2014: 133). Cyberspace, therefore, with a governance structure originally intended only for its technical, architectural considerations, was a natural fit for a security dilemma to ultimately unfold, with intelligence agencies the natural actors to lead it. As Carlin notes, when it comes to geopolitics, cyberspace has become "an extension of the real world" (Carlin 2018: 79).

The exploitation of cyberspace by intelligence actors is undoubtedly leading to socio-technological uncertainties. That uncertainty, however, lies not in the actions or issues themselves, but rather the uncertainty of the outcome for the future of cyber security politics. Ultimately, the risk that is carried is that the behaviors of intelligence actors in the pursuit of security do indeed develop cyberspace into a true security dilemma, one that is fully entwined with the rest of the geopolitical world. This carries the potential for political fragmentation in two arenas that are already well known, that from within - the balance between security and liberty - and that from without - the fundamental geopolitical architecture on which espionage is grounded.

From within, this fragmentation greatly impacts a perennial issue among liberal societies, which is the balance between liberty and security, how far the state's power should justifiably extend into the rights of individuals. The Snowden leaks are the primary culprit in precipitating renewed public debate in how far the powers of the security state should extend, a debate that was renewed for the digital age. This is a battleground already joined worldwide, highlighting significant political fragmentation in the fundamental values by which states govern themselves. Are domestic laws seeking to assert their sovereignty, or protect their citizens' liberal values? Farrell and Newman are entirely correct in stating that "Questions of privacy, security, and information will be at the heart of many 


\section{Danny Steed}

political battles over the next century as information has at last been politicized" (Farrell and Newman 2019: 63, italics added).

The clearest battleground where this can be seen worldwide is the imposition of various data localization laws, all aimed to establish sovereign authority over information itself. In the UK, the controversial Investigatory Powers Act, 2016 commonly dubbed "The Snoopers Charter" - provides the British intelligence services a new legal framework to enable bulk collection practices, while mandating that internet service providers retain records for 12 months, to facilitate law enforcement investigation where needed. Many similar statutory acts worldwide mandate data storage in-country, ensuring access by legal authorities. Russia's Federal Law No. 242-FZ carries the most expansive position, however, in declaring authority over the data of all Russian citizens regardless of where in the world both the individual and their data resides.

Fragmentation in cyber security politics is already happening worldwide, with efforts to establish sovereign authority over data itself a raging battleground of competing legislation claiming legitimacy, but across a spectrum of interpretations on where one's own sovereignty extends to. These acts also enable intelligence and law enforcement intrusion with varying, if any, transparency over the methods and legal practices permitting access. The fragmentation of cyber security politics within states is made clearest by the current creation and establishment of data localization laws worldwide; this is an arena that should be researched carefully in order to better understand how the uncertainty of the balance between security and liberty will play out.

From without, Inkster is right to state that a "battle for the soul of the Internet" is being waged (Inkster 2016: chapter 4), where political fragmentation is threatened over the fundamental mechanics to govern the internet itself. As this author has previously argued, cyberspace grew in an "apolitical honeymoon" (Steed 2019: 32) period in the immediate post-Cold War years, providing a form of incubator to protect its nascent growth from significant geopolitical challenge that it no longer enjoys. Kello has argued that a "sovereignty gap" exists in cyberspace (Kello 2017: 254), which has become the scene for political fragmentation as a new geopolitical battle begins to be waged for control of it; that gap itself is not the source of fragmentation, it is the growing competition to fill the gap that is. The resulting socio-technological uncertainty that is faced is simple, which geopolitical vision wins this battle for the soul of the internet?

For authoritarian nations, cyberspace and the internet have always been viewed as threats to their national security, for the liberal West, they were seen as tools of liberation for the individual and a mechanism for prosperity to the market-driven state. These perspectives are reflections of respective strategic cultures adapting to the presence of cyberspace, cultures which are "deeply rooted in history, economics, and strategic challenges" (Segal 2016: 361) that extend far beyond the experience of only the internet. Hughes Wilson rightly, although incompletely, identifies the key issues facing these core protagonists in the future of cyber security politics. "For China and other autocratic governments, the priority is to control citizens" access to information; whereas for the more liberal West, the key 
concern is the struggle to protect intellectual property rights and technological supremacy" (Hughes Wilson 2017: 635). Hughes Wilson's view is incomplete in failing to identify the West's battle to protect the balance between security and liberty as an additional key domestic concern. It should be clear, however, that the trajectory of cyber security politics has extended far beyond the original concerns of intelligence actors, who sought simply to adapt to the digital age and ensure continued access to information. Their actions have arguably contributed to creating one of the biggest geopolitical battlegrounds of the 21 st century.

\section{Conclusion}

This chapter began with the intent of mapping some of the impacts and changes that cyberspace and cyber security brought to the business of intelligence actors. Throughout, however, it has become clear that the socio-technological challenges posed by cyberspace to those in the intelligence world, and the adaptations taken by those actors to maintain their value as national security instruments, have resulted in a more significant conclusion. This is that the impact of intelligence upon cyber security carries more significant consequences to political fragmentation and cyber security politics than the impacts of cyberspace upon how the intelligence services conducts their affairs.

There are three broad conclusions to offer underneath this overarching position. First, the socio-technological transformations brought with cyberspace have fundamentally affected, if not altered entirely, the meaning of secrecy in the modern world, carrying with it significant effects on the intelligence profession. It has been seen that with a "declining half-life" of secrecy affecting even those intelligence services with historically excellent records at keeping secret even their existence, the meaning and value of both secrecy and secrets themselves is evolving in ways clearly not anticipated.

Broeders is right to note that, unlike in the past, the collection of information itself is "less the issue than keeping secret the fact you are collecting it" (Broeders 2016: 302), which has also been made increasingly difficult by the exposure of intelligence methods and tools. Combined with the rise of the post-trust world, where accepted realities are subject to distortion and challenge, and "virality can overwhelm truth" (Singer and Brooking 2019: 46), increased pressure is placed on an old challenge. This is whether it is the duty of intelligence to remove or assess uncertainty itself. Intelligence Studies may need to revise its traditional view that the latter is to be sought (Friedman and Zeckhauser 2012: 845) in light of continued concerns around election interference and the resurgence of disinformation campaigns.

Second, that intelligence has become a dominant source of proliferation, enabling the multitudes of diverse actors that also share and use cyberspace. A form of "collateral damage" now accompanies intelligence work that must sift through the stacks of data gathered from the civilian population at large. If the "whole haystack" must be collected, then it becomes surely inevitable that some kind of impact will be felt among those within the haystack. Additionally, and 


\section{Danny Steed}

closely linked to the declining half-life of secrecy, is the exposure of intelligence sources and methods more routinely. By moving from passive to ever more proactive gatherers of information, intelligence services pioneer methods in intrusion, exploitation, and analysis that proliferate.

This proliferation, which has ranged from code exploits such as EternalBlue, through to understanding of OSINT methodology and big data analytics, has been adopted and reverse engineered elsewhere. This includes innovations by adversary nations also pursuing their geopolitical ambitions, but also to large corporates, hacktivist groups, organized crime, journalistic bodies, and even technically capable individuals. The linkages behind the intelligence agency that (allegedly) developed Stuxnet attack to the recycled variant of the Flame virus unleashed widely, and the EternalBlue exploit compromise being used in both the WannaCry and NotPetya attacks, should not be underestimated.

With intelligence agency sources, methods, and tools now subjected to greater exposure than ever before, the final conclusion should not be surprising. That conclusion is that intelligence agency behavior is incentivized by traditional security perspectives, but that very pursuit is also strongly contributing to ever increased cyber insecurity, creating a new manifestation of the security dilemma in the 21 st century. Kello's view that every advancement "invites its dangers" (Kello 2017: 256) and contributes to a dynamic of deceasing security accompanies not only advances in technology, but so too in the path of intelligence community behavior. Dunn Cavelty's observation that information operations blur not only the boundaries between civilian and military objectives, but those between war and peace itself (Dunn Cavelty 2008: 142), serve to illustrate the uncertainty and accompanying insecurity such activities bring. This is a point that Singer and Brooking also insist upon in stating that "war and politics have never been so intertwined" in an environment where all are participants, making us "all part of the battle" (Singer and Brooking 2019: 493-494, italics original).

The intelligence community, in their search for answers to the questions of how to remain relevant, operate within, and exploit cyberspace in pursuit of national security objectives, have become disproportionate influencers of norms in the international system. Georgiva is entirely correct in arguing that the intelligence community in their deployment of disruptive cyber tools have become "unexpected norm-setters" (Georgiva 2020), yet it must be realized that their behavior carries more significant consequences related to political fragmentation. These are all dynamics worthy of further scholarly attention, both from Intelligence Studies to better consider the impact of cyber security upon both the practice and study of intelligence, but also from international relations scholars too. For if a key geopolitical battleground of the 21 st century is the fragmentation of cyber security politics, then the impact of intelligence actor behavior has already proven to be a dominant consideration for researchers. Through its actions to adapt to the digital age, the second oldest profession has disrupted the politics of cyber security in ways that carry great consequences to the geopolitics of the 21 st century. 


\section{Acknowledgment}

The author wishes to thank Dennis Broeders and the Cyber Norms Program at the University of Leiden. Their Visiting Fellowship Program I was fortunate enough to be part of was invaluable in the development of this chapter.

\section{Note}

1 Typically credited to Mitchell Kapor, but acknowledged as being without definitive source and a variation on a similar phrase from generations past. https://cyber.harvard .edu/archived_content/people/reagle/inet-quotations-19990709.html

\section{References}

All links checked on August 23, 2021.

Adams, J. (1994). The New Spies: Exploring the Frontiers of Espionage. London: Pimlico. Andrew, C. (2018). The Secret World: A History of Intelligence. New Haven, CT: Yale University Press, Apple iBooks edition.

Andrew, C., and Dilkes, D. (eds). (1985). The Missing Dimension: Governments and Intelligence Communities in the Twentieth Century. Basingstoke: Macmillan.

Berners-Lee, T. (1991, August 6). Tim Posting to the Newsgroup alt.hypertext. Retrieved from: https://www.w3.org/People/Berners-Lee/1991/08/art-6484.txt.

Brantly, A. F. (2014). The Cyber Losers. Democracy and Security, 10(2): 132-155.

Broeders, D. (2016). The Secret in the Information Society. Philosophy and Technology, 29(3): 293-305.

Broeders, D., Boeke, S., and Georgiva, I. (2019). Foreign Intelligence in the Digital Age: Navigating a State of 'Unpeace'. Leiden: The Hague Program for Cyber Norms Policy Brief, September.

Buchanan, B. (2020). The Hacker and the State: Cyber Attacks and the New Normal of Geopolitics. Cambridge, MA: Harvard University Press, Apple iBooks edition.

Carlin, J. P. (2018). Dawn of the Cold War: America's Battle against Russia, China, and the Rising Global Cyber Threat. New York: Public Affairs, Apple iBooks edition.

Clemente, D. (2014). Cybersecurity. In R. Dover, M. S. Goodman, and C. Hillebrand (eds), The Routledge Companion to Intelligence Studies. Abingdon: Routledge, pp. 256-263.

Degaut, M. (2016). Spies and Policymakers: Intelligence in the Information Age. Intelligence and National Security, 34(1): 509-531.

Dunn Cavelty, M. (2008). Cyber-Security and Threat Politics: US Efforts to Secure the Information Age. Abingdon: Routledge.

Dunn Cavelty, M. (2018a). Aligning Security Needs for Order in Cyberspace. In H. W. Maull (ed.), The Rise and Decline of the Post-Cold War International Order. Oxford: Oxford University Press, pp. 104-119.

Dunn Cavelty, M. (2018b). Cybersecurity Research Meets Science and Technology Studies. Politics and Governance, 6(2): 22-30.

Farrell, H., and Newman, A. L. (2019). Of Privacy and Power: The Transatlantic Struggle over Freedom and Security. Princeton, NJ: Princeton University Press. 


\section{Danny Steed}

Friedman, J. A., and Zeckhauser, R. (2012). Assessing Uncertainty in Intelligence. Intelligence and National Security, 27(6): 824-847.

Georgiva, I. (2020). The Unexpected Norm-Setters: Intelligence Agencies in Cyberspace. Contemporary Security Policy, 41(1): 33-54.

Gill, P., and Phythian, M. (2018). Intelligence in an Insecure World (3rd ed.). Cambridge: Polity Press.

Griffiths, M., O'Callaghan, T., and Roach, S. C. (2002). International Relations: The Key Concepts Second Edition. Abingdon: Routledge.

Greenberg, A. (2019). Sandworm. New York: Doubleday, Apple iBooks edition.

Greenwald, G. (2014). No Place to Hide: Edward Snowden, the NSA and the Surveillance State. New York: Penguin Books, Apple iBooks edition.

Harding, L. (2014). The Snowden Files: The Inside Story of the World's Most Wanted Man. New York: Vintage Books, Apple iBooks edition.

Hayden, M. V. (2016). Playing to the Edge: American Intelligence in the Age of Terror. New York: Penguin, Apple iBooks edition.

Herrington, L. (2020). The New Frontier: Cyberespionage and Cyberwar. In C. Andrew, R. J. Aldrich, and W. K. Wark (eds), Secret Intelligence: A Reader (2nd ed.). Abingdon: Routledge, pp. 566-83.

Hughes Wilson, J. (2017). The Secret State: A History of Intelligence and Espionage. New York: Pegasus Books, Apple iBooks edition.

Inkster, N. (2016). China's Cyber Power. London: IISS.

Jervis, R. (2007). CooperationUnder the Security Dilemma. In B. Buzan and L. Hansen (eds). International Security, Volume I: The Cold War and Nuclear Deterrence. London: SAGE Publications.

Kaplan, F. (2017). Dark Territory: The Secret History of Cyber War. New York: Simon and Schuster, Apple iBooks edition.

Kello, L. (2017). The Virtual Weapon and International Order. London: Yale University Press.

Lin, H., and Zegart, A. (2018). Introduction. In H. Lin and A. Zegart (eds), Bytes, Bombs and Spies: The Strategic Dimensions of Offensive Cyber Operations. Washington, DC: Brookings Institution Press, pp. 1-17.

Lowenthal, M. M. (2018). The Future of Intelligence. Cambridge: Polity, Apple iBooks edition.

Lustgarten, L., and Leigh, I. (1994). In from the Cold: National Security and Parliamentary Democracy. Oxford: Clarendon Press.

MacAskill, E., Borger, J., Hopkins, N., Davies, N., and Ball, J. (2013, June 21). Mastering the Internet: How GCHQ Set Out to Spy on the World Wide Web. The Guardian. Retrieved from: https://www.theguardian.com/uk/2013/jun/21/gchq-mastering-the-internet.

Nakashima, E., and Warrick, J. (2013, July 14). For NSA Chief, Terrorist Threat Drives Passion to 'Collect it All'. The Washington Post. Retrieved September 16, 2018, from: https://www.washingtonpost.com/world/national-security/for-nsa-chief-terrorist-threat -drives-passion-to-collect-it-all/2013/07/14/3d26ef80-ea49-11e2-a301-ea5a8116d211 story.html?noredirect $=$ onandutm_term $=.3846 \mathrm{af} 9 \mathrm{dab} 73$.

National Audit Office. (2018, April 25). Investigation: WannaCry Cyber Attack and the NHS, HC 414. Retrieved from: https://www.nao.org.uk/report/investigation-wannacry -cyber-attack-and-the-nhs/. 
Obama, B. (2015, February 13). Remarks by the President at the Cybersecurity and Consumer Protection Summit. Retrieved from: https://obamawhitehouse.archives.gov/ the-press-office/2015/02/13/remarks-president-cybersecurity-and-consumer-protection -summit.

Rid, T., and McBurney, P. (2012). Cyber-Weapons. RUSI Journal, 157(1): 6-13.

Sanger, D. E. (2018). The Perfect Weapon: War, Sabotage, and Fear in the Cyber Age. New York: Crown, Apple iBooks edition.

Schmitt, M. N. (ed.) (2017). Tallinn Manual 2.0 on the International Law Applicable to Cyber Operations. Cambridge: Cambridge University Press.

Schneier, B. (2018). Click Here to Kill Everybody: Security and Survival in a HyperConnected World. New York: W. W. Norton and Company, Apple iBooks edition.

Segal, A. (2016). The Hacked World Order: How Nations Fight, Trade, Maneuver, and Manipulate in the Digital Age. New York: Public Affairs, Apple iBooks edition.

Singer, P. W., and Brooking, E. T. (2019). Like War: The Weaponisation of Social Media. New York: Houghton Mifflin Harcourt, Apple iBooks edition.

Snowden, E. (2019). Permanent Record. New York: Macmillan, Apple iBooks edition.

Steed, D. (2019). The Politics and Technology of Cyberspace. Abingdon: Routledge.

Swire, P. (2015). The Declining Half-Life of Secrets and the Future of Signals Intelligence. New America Cybersecurity Fellows Paper - Number 1, July. Retrieved from: https:// www.newamerica.org/cybersecurity-initiative/policy-papers/the-declining-half-life-of -secrets/.

Tucker, D. (2014). The End of Intelligence: Espionage and State Power in the Information Age. Stanford, CA: Stanford University Press.

Valeriano, B., Jensen, B., and Maness, R. C. (2018). Cyber Strategy: The Evolving Character of Power and Coercion. Oxford: Oxford University Press.

Van Puyvelde, D., and Brantly, A. F. (2019). Cybersecurity: Politics, Governance and Conflict in Cyberspace. Cambridge: Polity.

Whyte, C., and Mazanec, B. (2019). Understanding Cyber Warfare: Politics, Policy, and Strategy. Abingdon: Routledge. 